\title{
ANÁLISE SOCIOAMBIENTAL SOBRE OS REFLEXOS DA DESERTIFICAÇÃO NO PÓLO DE JEREMOABO: AS CRIANÇAS E OS JOVENS NO MUNDO DO TRABALHO Aryane Sinval Alves ${ }^{1}$; Nacelice Barbosa Freitas ${ }^{2}$
}

1. Bolsista PIBIC/CNPq, Graduando em Bacharelado em Geografia, Universidade Estadual de Feira de Santana, email: aryanesalves@gmail.com

2. Orientador, Departamento de Ciências Humanas e Filosofia (DCHF), Universidade Estadual de Feira de Santana, e-mail: nacegeografic@hotmail.com

PALAVRAS-CHAVE: Migração; Desertificação e Trabalho.

\section{INTRODUÇÃO}

Este resumo tem por objetivo analisar os dados sociodemográficos do Pólo de Jeremoabo ao indicar os números das crianças e os jovens no mundo do trabalho, explicando a relação com o processo de desertificação. O mundo do trabalho dentro do modo de produção capitalista se forma a partir das relações sociais de produção, segundo Silva (1999) a utilização dessa faixa etária no processo produtivo "tem a sua razão de ser baseadas nas relações sociais capitalistas e se estabelece com o novo modo de produzir. Ela não é resultado da vontade das famílias dos trabalhadores, muito menos de determinada tradição cultural. Para explicar o mundo do trabalho na idade infantojuvenil em áreas de vulnerabilidade socioambiental é necessário compreender como ocorrem dois processos, o primeiro se estabelece pela inserção da mão de obra infantil e dos jovens no processo de produção da agricultura familiar, extrativismo, e agropastoril, e o segundo pela busca de sobrevivência na cidade.

Sua relevância vem da necessidade de analisar o fenômeno a partir da realidade, sendo este essencial para a permanência da população, valorização cultural e desenvolvimento socioeconômico do Pólo, pois, essa faixa etária das crianças e dos jovens também é atingida pelos reflexos vulnerabilidade ambiental, sendo assim, pensar no contingente populacional, buscando identificar os problemas socioambientais contribui para implementação de estratégias que mitiguem os efeitos da desertificação, e reafirmando, então, a ideia de convivência com o semiárido.

A discussão tem como caminho a identificação dos dados sociodemográficos referentes às crianças e os jovens no mundo do trabalho do Pólo de Jeremoabo, especificamente trabalho infantil, trabalho pela população jovem, e o nível de escolaridade entre 2000 e 2010, relacionando com as causas e consequências do processo de desertificação, através do mapeamento dessas informações, onde será possível indicar os espaços de maior vulnerabilidade ambiental e susceptíveis à desertificação no Pólo de Jeremoabo.

\section{MATERIAL E MÉTODOS}

Para a realização da pesquisa foi utilizado o método estatístico-comparativo, onde ocorrerá o confronto entre os dados estatísticos, de tal forma que seja possível analisar os indicadores sociodemográficos, por meio da comparação e evolução dos mesmos, especificamente sobre trabalho e migração, pelo número de pessoas que não estão inseridas nas atividades laborais, e posteriormente explicar a relação desses números com o processo de desertificação. Realizou-se o levantamento bibliográfico dos conceitos de Trabalho, e Trabalho Infanto-juvenil, posteriormente ocorreu a 
sistematização dos dados e mapeamento socioespacial das informações. Tais procedimentos têm por objetivo relacionar os indicadores sociodemográficos com o processo de desertificação, através do estudo dos movimentos migratórios tomando como referência a categoria Trabalho, sob o enfoque da inserção das crianças e dos jovens que ainda não estão em idade de trabalho, como também os que estão em idade de estudar e trabalhar.

Os municípios que integram o Polo de Jeremoabo, são eles: Canudos, Uauá, Macururé, Rodelas, Chorrochó, Paulo Afonso, Glória, Santa Brígida, Pedro Alexandre, Coronel João Sá, Novo Triunfo, Antas e Jeremoabo. (FIGURA 1)

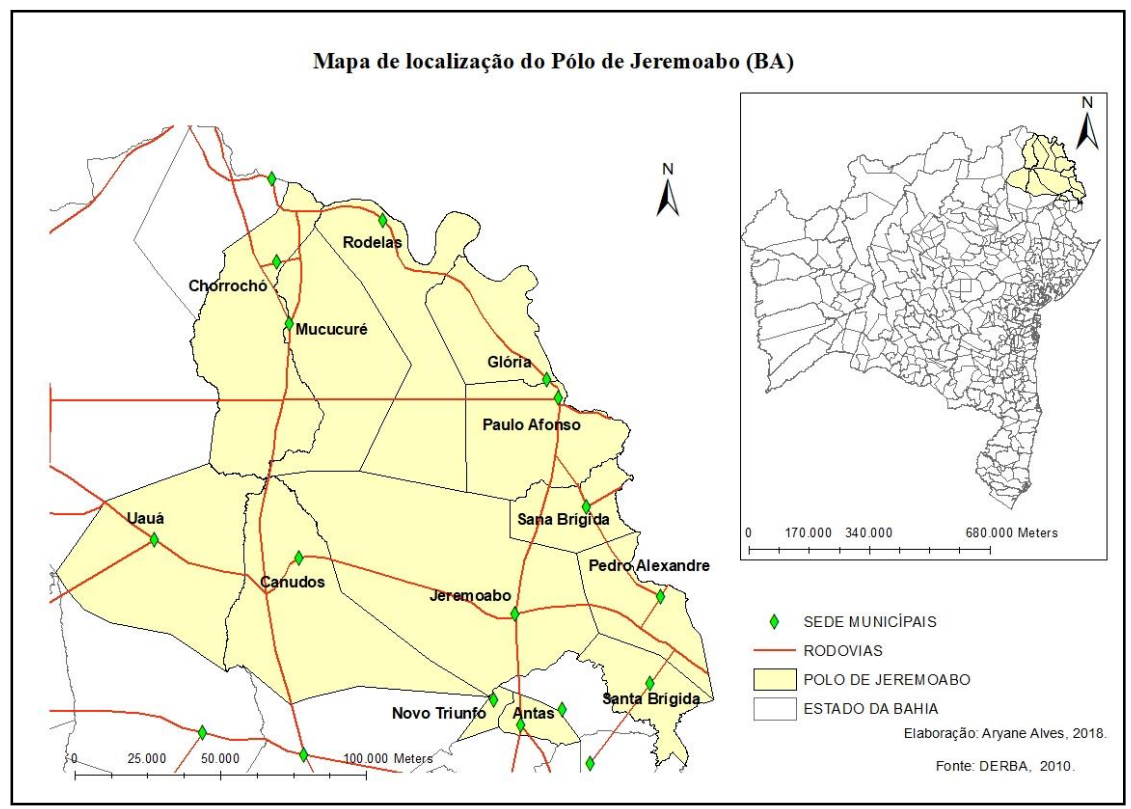

Figura 01: Pólo de Jeremoabo: localização dos municípios no Estado da Bahia

Estes espaços foram definidos a partir da identificação dos elementos definidores do processo de desertificação. Localizam-se na parte nordeste do estado da Bahia, na área de domínio morfoclimáticos do semiárido. O Semiárido é caracterizado segundo Sá e Silva (2010) por possuir uma vegetação adaptada às condições de semiaridez, de fisionomia variada, denominada Caatinga.

\section{RESULTADOS E/OU DISCUSSÃO}

Analisar os dados socioeconômicos e educacionais permite identificar os elementos que compõem esse fenômeno, a partir dos dados de trabalho infantil, e trabalho pela população jovem, e o nível de escolaridade será possível então, identificar o panorama socioespacial do Pólo de Jeremoabo, e relacionar as susceptibilidades presentes em áreas de vulnerabilidade socioambiental. A tabela 1 apresenta informações a respeito do trabalho infanto-juvenil do Pólo de Jeremoabo em 2000 e 2010.

Tabela 1: Pólo de Jeremoabo: Proporção de pessoas de 10 anos ou mais de idade, ocupadas na semana de referência (\%), por grupos de idade (2000-2010)

\begin{tabular}{lrrrr}
\cline { 2 - 5 } \multicolumn{1}{c}{ Municípios } & $\mathbf{2 0 0 0}$ & $\mathbf{2 0 0 0}$ & $\mathbf{2 0 1 0}$ & \multicolumn{2}{c}{$\mathbf{2 0 1 0}$} \\
\hline Antas & $\mathbf{1 0 - 1 7}$ anos & $\mathbf{1 8 - 2 4}$ anos & $\mathbf{1 0 - 1 7}$ anos & $\mathbf{1 8 - 2 4}$ anos \\
Canudos & 10,9 & 43,4 & 11,7 & 43,0 \\
Chorrochó & 8,7 & 35,4 & 15,7 & 57,5 \\
Coronel João Sá & 16,8 & 41,8 & 17,5 & 49,3 \\
& 5,1 & 29,9 & 21,0 & 57,9
\end{tabular}




\begin{tabular}{lrrrr} 
Glória & 9,0 & 36,1 & 12,2 & 49,8 \\
Jeremoabo & 20,1 & 49,0 & 27,8 & 63,2 \\
Macururé & 26,3 & 64,0 & 14,5 & 53,1 \\
Novo Triunfo & 18,9 & 52,4 & 16,0 & 48,7 \\
Paulo Afonso & 10,5 & 43,0 & 11,3 & 68,4 \\
Pedro Alexandre & 18,1 & 51,5 & 22,9 & 55,7 \\
Rodelas & 21,1 & 42,5 & 8,9 & 47,8 \\
Santa Brígida & 32,2 & 58,3 & 36,4 & 62,7 \\
Uauá & 9,9 & 37,9 & 13,4 & 51,7 \\
Total & $\mathbf{2 0 7 , 6}$ & $\mathbf{5 8 5 , 2}$ & $\mathbf{2 2 9 , 3}$ & $\mathbf{7 0 8 , 8}$ \\
\hline
\end{tabular}

Fonte: Censo Demográfico do Instituto Brasileiro de Geografia e Estatística (IBGE2000-2010)

De acordo com as informações sobre os indicadores sociais no que se refere a crianças e adolescente que trabalharam no período entre 2000 e 2010, percebe-se que a faixa etária entre 10 a 17 anos, o número de crianças exercendo ocupação aumentou, de 207,6 pessoas para 299,3 pessoas. A faixa etária correspondente a 18 até 24 anos também houve crescimento nos valores: ampliou de 585,2 jovens para 708,0 jovens integrados ao mundo do trabalho, no Pólo de Jeremoabo.

Os dados apresentados na tabela 2 trazem informações a respeito da taxa de escolarização infanto-juvenil e de analfabetismo do Pólo de Jeremoabo em 2000 e 2010. Tabela 2: Pólo de Jeremoabo: Taxa de escolarização por grupos de idade (\%) em (2000) e taxa de analfabetismo por grupos de idade (\%) em 2010.

\begin{tabular}{|c|c|c|c|c|}
\hline Municípios & 2000 & 2000 & 2010 & 2010 \\
\hline & 15-17 anos & 18-24 anos & 10-13 anos & 10-17 anos \\
\hline Antas & 77,9 & 29,9 & 9,6 & 5,1 \\
\hline Canudos & 74,7 & 26,0 & 7,9 & 5,0 \\
\hline Chorrochó & 76,1 & 37,2 & 13,2 & 10,8 \\
\hline Coronel João Sá & 59,9 & 26,3 & 6,2 & 5,5 \\
\hline Glória & 78,3 & 35,6 & 10,1 & 8,0 \\
\hline Jeremoabo & 71,4 & 37,4 & 10,7 & 6,9 \\
\hline Macururé & 79,5 & 40,9 & 13,8 & 9,1 \\
\hline Novo Triunfo & 83,6 & 40,2 & 5,1 & 4,6 \\
\hline Paulo Afonso & 79,6 & 37,3 & 7,9 & 6,3 \\
\hline Pedro Alexandre & 60,0 & 31,2 & 27,9 & 21,5 \\
\hline Rodelas & 79,9 & 35,0 & 14,7 & 10,7 \\
\hline Santa Brígida & 75,4 & 42,9 & 11,6 & 7,8 \\
\hline Uauá & 87,1 & 41,4 & 4,5 & 4,6 \\
\hline
\end{tabular}

Em 2000, identifica-se o número crianças e adolescentes que frequentaram a escola, representados pela a taxa de analfabetismo, ao comparar com os valores dos dados de 2010, percebe-se que quando a idade vai saindo da fase de pré-adolescência indo em direção a maior idade, o número de pessoas que frequentaram a escola vai depender de cada município, destaca-se os município de Coronel João Sá e Pedro Alexandre como sendo os que apresentaram maiores índices de analfabetismo, logo, o número de crianças e jovens que frequentaram a escola é menor. (TABELA 02)

A tabela 3 é para identificar os espaços de maior vulnerabilidade ambiental e susceptíveis à desertificação no Pólo de Jeremoabo a partir da leitura sobre o trabalho infanto-juvenil do Pólo de Jeremoabo em 2000 e 2010. 
Tabela 3: Percentual de pessoas em atividade da agricultura, pecuária, produção florestal, pesca e aquicultura no trabalho principal na população de 10 a 17 anos de idade em 2010.

\begin{tabular}{lcc}
\multicolumn{1}{c}{ Municípios } & $\mathbf{2 0 1 0}(\%)$ \\
\cline { 2 - 3 } Antas & $\mathbf{1 0 - 1 7}$ anos \\
Canudos & 57,9 \\
Chorrochó & 69,9 \\
Coronel João Sá & 65,6 \\
Glória & 64,7 \\
Jeremoabo & 88,9 \\
Macururé & 79,0 \\
Novo Triunfo & 87,1 \\
Paulo Afonso & 80,8 \\
Pedro Alexandre & 32,8 \\
Rodelas & 86,8 \\
Santa Brígida & 45,6 \\
Uauá & 76,7 \\
\hline
\end{tabular}

Fonte: Censo Demográfico do Instituto Brasileiro de Geografia e Estatística (IBGE-2000-2010)

De acordo com a tabela 3 é possível identificar a porcentagem referente a quantidade de crianças e adolescente que trabalham no campo exercendo ocupação em atividades ligadas a produção agropastoril e extrativista no ano de 2010 no Pólo de Jeremoabo. Merecem destaque os municípios que tiveram os valores maiores que $70 \%$ em relação as demais localidades que integram área de estudo, pois, estes são os lugares onde a situação torna-se mais crítica, já que configuram áreas de vulnerabilidade socioambiental para essa faixa etária, são eles: Santa Brígida, Jeremoabo, Pedro Alexandre, Macururé e Glória, com 76,7 \%, 79,0\%, 86,8\%, 87,1\% e 88,9 \%, respectivamente.

\section{CONSIDERAÇÕES FINAIS}

O Pólo de Jeremoabo tem a maioria das crianças e adolescente trabalhando no campo, isso nos permite identificar a relação dos municípios com o trabalho rural $\mathrm{e}$ principalmente a sua ligação com a natureza, pois nessa situação, é fonte de sobrevivência, mas também de identidade.

Os municípios, na atualidade, encontram-se em estado preocupante referente aos dados de 2000 e 2010. Santa Brígida e Macururé, são aqueles que detém os maiores indicadores de trabalho infanto-juvenil. Em no que se refere aos índices educacionais Coronel João Sá e Pedro Alexandre tem as mais altas taxas de analfabetismo, e no que se refere ao trabalho ligado ás atividades agropastoril e extrativistas, Santa Brígida e Pedro Alexandre, apresentam os maiores índices.

\section{REFERENCIAS}

ANTUNES, Ricardo. Os sentidos do trabalho: ensaio sobre a afirmação e a negação do trabalho. 5 ed. São Paulo, Boitempo, 2001.

SÁ, Iêdo Bezerra; SILVA, Pedro Carlos Gama. Semiárido Brasileiro: pesquisa, desenvolvimento e inovação. Pernambuco: Embrapa Semi-Árido, 2010402 p.

SILVA, Francisco Carlos Lopes da. O trabalho infanto-juvenil na sociedade capitalista. (Dossiê - Crianças e Adolescentes Excluídos: ações e reflexões) Educar em Revista, $\mathrm{N}^{\mathrm{o}} .15$, Curitiba, 1999. 